\title{
A field study of the exposure-annoyance relationship of military shooting noise
}

\author{
Mark Brink ${ }^{\text {a) }}$ \\ D-MTEC Public and Organizational Health, ETH Zurich, CH-8092 Zurich, Switzerland \\ Jean-Marc Wunderli \\ Laboratory of Acoustics, Empa Swiss Federal Laboratories for Materials Testing and Research, CH-8600 \\ Duebendorf, Switzerland
}

(Received 20 April 2009; revised 15 December 2009; accepted 6 February 2010)

\begin{abstract}
This article reports a field study on noise annoyance from military shooting with small, midsize, and heavy weapons that was carried out among 1002 residents living near eight different training grounds of the Swiss army. The goal of the study was to derive the exposure-annoyance relationship for military shooting noise in communities in the vicinity of average military training grounds. Annoyance was determined in a telephone survey by means of the 5-point verbal and 11-point numerical annoyance scale recommended by the International Commission on Biological Effects of Noise. Exposure was calculated using acoustical source models of weapons and numbers of shots fired, as recorded by the army. Annoyance predictor variables investigated were $L_{\mathrm{AE}}, L_{\mathrm{CE}}, L_{\mathrm{CE}}$ $-L_{\mathrm{AE}}$, number of shots above threshold, as well as individual moderators. Exposure-annoyance relationships were modeled by means of linear and logistic regression analyses. The sound exposure level $L_{E}$ of shooting noise better explained variations in annoyance than other operational and/or acoustical predictors. Annoyance on the 5-point scale was more closely related to noise exposure than expressed on the 11-point scale. The inclusion of the C-A frequency weighting difference as a second explaining variable, as suggested earlier, did not substantially enhance the predictability of high annoyance. () 2010 Acoustical Society of America. [DOI: 10.1121/1.3337234]
\end{abstract}

PACS number(s): 43.50.Qp, 43.50.Pn, 43.50.Sr [BSF]

Pages: 2301-2311

\section{INTRODUCTION}

\section{A. Study rationale}

Exposure-response relationships are commonly used to assess the annoyance impact of many kinds of traffic or industrial noise. In their most common form, they relate noise exposure to the percentage of highly annoyed persons (\%HA). As military shooting noise (as a result of military training activities in times of peace) is less of a problem for the majority of the population, there exist only a few field studies in the literature that investigated its effects. Hence the impact of military shooting noise from training grounds of armies is far less well understood than effects of other noise sources. The goals of the current study were thus the establishment of a statistical model that explains variation of community annoyance by operational and acoustical descriptors of military shooting activity and to provide an exposureeffect function for high annoyance (\%HA) among residents in the vicinity of typical military training grounds in Switzerland.

Despite a relatively large body of literature, which mostly pertains to laboratory studies (Meloni and Rosenheck, 1995; Schomer et al., 1994; Vos, 2001, 2003; Vos and Geurtsen, 2003), there have only few exposure-effect functions for (military) shooting noise been published so far (e.g., in Schomer, 1985). In the real-world situation, people use

\footnotetext{
a) Author to whom correspondence should be addressed. Electronic mail: brink@ethz.ch
}

adaptive mechanisms that try to ignore noise as much as possible, whereas in a laboratory setting they do the opposite and inevitably concentrate on the noise. This provides a strong rationale to investigate shooting noise effects in the field, at the homes of the affected population.

The current study was carried out in Switzerland, where one can find several multipurpose training grounds where military shooting activity comprises small, middle, and heavy weapon shooting in one and the same place, and, because plain space is very scant, often in close vicinity to inhabited areas. This specific geographic situation therefore appears to be well suited to investigate military shooting noise annoyance by means of a field study. At this point, the notion is relevant that this study is not primarily about the effects of large army weapons such as tanks or artillery, since the number of rounds of such types of weapons each year is considerably lower than from small caliber arms.

\section{B. Shooting noise descriptors and exposure-effect relationships}

While exposure assessment following the equal energy principle has been adopted for the most distinctive noise sources, at least pertaining to annoyance as dependent variable, no commonly accepted noise descriptor for assessing community annoyance to shooting noise has successfully established itself to date. Of the few field studies on community annoyance due to weapon noise at hand (Buchta and Vos, 1998; Bullen and Hede, 1982; Fidell et al., 1983; Levein and Ahrlin, 1988; Rylander and Lundquist, 1996; 
Schomer, 1985; Schomer et al., 1994; Sorensen and Magnusson, 1979), only few exposure-effect functions explaining annoyance due to a mixture of different kinds of army weapons emerged.

In the literature, noise descriptors that were identified to yield the highest degrees of explained variance of annoyance from impulsive sounds vary from accumulated peak level (Bullen et al., 1991), maximum sound pressure level (Levein and Ahrlin, 1988), A-weighted FAST maximum sound pressure level (Sorensen and Magnusson, 1979), number of shots above a C-weighted threshold level (Rylander and Lundquist, 1996), C-weighted average day-night level $L_{\mathrm{CDN}}$ (Schomer, 1985), and Schomer's (Schomer, 1994) "new descriptor for high-energy impulsive sounds" (Buchta and Vos, 1998), the $L_{\text {Aeq }}$, to even surrogate measurements of ground vibration in the case of blast noise from surface mines (Fidell et al., 1983). Most of these studies investigated the noise effect from particular source (weapon) types, either from, e.g., rifle shooting ranges or from large weapon training facilities. Shooting with firearms on multipurpose training grounds with different combinations of small to very large caliber weapons creates a complex blend of different sounds. It therefore appears that the construction of an all-purpose exposure-effect curve regarding military shooting noise is much more difficult than for other more uniform noise types. Depending on the predominant weapon type used, one or the other noise descriptor probably better predicts community annoyance. For example, noise annoyance from large weapons which also elicit rattle and vibrations might better be predicted using a $\mathrm{C}$-weighted measure than an A-weighted measure. The question which predictor best accounts for the variation of military shooting noise annoyance in general, that means for any kind and combination of weapons, cannot easily be answered.

\section{Frequency weighting}

The question of the choice of frequency weighting to best predict impulsive or weapon noise annoyance respectively has received considerable attention in the literature. Insights into the relationship between shots of weapons and annoyance, especially with regard to impulse correction and frequency weighting have been collected in a series of laboratory studies (Meloni and Rosenheck, 1995; Schomer and Wagner, 1995; Schomer et al., 1994; Vos, 1990, 2001). The use of the A-weighting is widespread in the evaluation of gunfire noise from small arms, usually including a penalty correction of between 5 and $12 \mathrm{~dB}$ for the added annoyance of impulsive sounds (Buchta, 1990; Vos, 1990). However, for the assessment of large caliber or high-energy weapon noise, the $\mathrm{C}$ weighting and the measure $L_{\mathrm{CE}}$ (or $L_{\mathrm{CDN}}$ ) have been suggested in the past (Schomer, 1986) or are recommended in ISO 1996-1 (International Standards Organisation, 2003). The assessment methodology applied in many European countries uses $L_{\mathrm{AF} \text {,max }}$ (Germany, Switzerland) or $L_{\mathrm{AI} \text {,max }}$ (Austria, Finland, Denmark, Norway, and Sweden) for small arms, and C-weighted measures such as $L_{\mathrm{CE}}$ (Finland, Norway, Sweden) and $L_{\mathrm{Ceq}}$ (Germany, The Netherlands, and Denmark) for large weapons.
For the whole set of impulse sound types produced by various firearms ranging in caliber from 7.62 to $155 \mathrm{~mm}$, the annoyance rating in the laboratory study of Vos (2001) was almost entirely determined by the "outdoor" $L_{\mathrm{AE}}$ of the impulses, as long as the artificial laboratory situation reflected a scenario with open windows. Similar results were reported by Meloni and Rosenheck (1995) who found that if shooting noise is predominantly heard through open windows, the A-weighted sound exposure level is appropriate for predicting annoyance.

Vos (2001) suggested to include the difference between the C- and A-weighted levels as a second annoyance predictor alongside the A-weighted level as principal predictor (Vos, 2001). Because the addition of the C-weighted level in the regression equations in most instances only very slightly increased the explained variance of the exposure-effect relationship, it remains arguable, whether the additional effort of C-weighted measurements and/or calculations is justified, particularly for the assessment of the "outside situation," as Vos $(2001,2003)$ demonstrated in his laboratory studies. It is therefore desirable to empirically test the advantage of the incorporation of $\mathrm{C}$-weighted measurements not only in the laboratory but also within the scope of community reaction surveys in the field, such as the present one.

\section{METHODS}

\section{A. Sampling procedure}

Depending on the site-specific combinations of weapons/ammunition used, average distances of dwellings from the shooting ground, the degree of visibility of army activities in the surrounding neighborhood, involvement with the army (e.g., as employee), and many other factors, one would expect exposure-effect relationships for annoyance to show a rather wide variation. As the primary goal of the study was collecting data for constructing an exposure-effect relationship, a representative amount of residents near the eight largest training grounds of the Swiss army, that were located sufficiently close to inhabited areas to potentially evoke annoyance reactions from noise, were sampled. The corresponding sites were the army training grounds of Bière, Thun, Wangen an der Aaare, Gehren-Erlinsbach, KrähtalRiniken, Walenstadt, Herisau-Gossau, and Chur. At each of these eight sites, the exposure contours from preliminary exposure calculations (that did not account for elevation above ground and shielding effects from neighboring buildings) were used to assign exposure values to building addresses using a GIS system provided by the Swiss statistics office. The exposure was calculated as the yearly sound exposure level $L_{\mathrm{AE}}$, i.e., the total acoustic energy resulting from shooting activity during an entire year. At each of the eight sites, the primary sampling area was defined as the area that was enclosed by the $104 \mathrm{~dB} L_{\mathrm{AE}}$ exposure contour. Each address was then assigned an exposure stratum (104-107, 107-110, $110-113,113-116,116-119,119-122,122-125,125-128$, and $>128 \mathrm{~dB}$ ). Over all eight sites, a total of 5901 building addresses within the $104 \mathrm{~dB}(\mathrm{~A})$ contour were identified. These addresses were aligned with a commercial address database to yield all available landline telephone numbers of 
households. 5851 individual telephone numbers were identified. The telephone numbers were stored together with their exposure level category and served as the primary sample. The survey was carried out by computer assisted telephone interviews (CATIs). Within each household, one person over 16 years of age was selected using a modified TroldahlCarter method (Troldahl and Carter, 1964). The CATI software was configured to try to sample equal amounts of subjects in the different exposure strata, as far as possible. 5851 individual numbers were called. A total of 1002 interviews could be realized. 2137 calls were either never answered or were not valid due to technical reasons (e.g., a FAX device at the other end of the line). Of the 3714 remaining calls that resulted in a voice contact, the following statistics apply: Valid interviews conducted: 27\%; interview scheduled, but did not take place for unknown reasons: $8 \%$; communication or language problems make interview impossible: $4 \%$; no target person living in household: $2 \%$; person called refused interview: $59 \%$.

\section{B. Telephone interviews}

Interviews lasted about 15-20 min and took place during the evening hours of September, October, and November 2007. The schedule moved gradually from questions about the satisfaction with the immediate environment to the topic of military shooting noise. The true aim of the survey was disclosed to all interviewees only after the interview was finished and they were given the opportunity to withdraw, an option no one exercised.

For the interviews, a questionnaire was used that first asked about various criteria of living quality of the interviewee, among them, noise exposure and annoyance from different sources (five-point verbal scale, including military shooting noise). These were asked in random order of the sources, followed by the items of the short form of the "Lärmempfindlichkeitsfragebogen" (LEFK; English: "Noise sensitivity questionnaire") by Zimmer and Ellermeier (1998) to assess noise sensitivity. In the middle of the interview, the main block about military shooting noise exposure and annoyance was placed. This main block of questions included the German version of the 11-point annoyance scale from 0 to 10 recommended by the International Commission on Biological Effects of Noise (ICBEN) that were published by Fields et al. (2001), a question about strategies to cope with the noise, and three items about the respondent's attitude toward the army (these items were "Switzerland does need an army," "The Swiss army sufficiently cares for the environment," and "Military shooting noise is a necessary evil") that had do be answered on a 1 to 5 scale with the end points "totally agree" and "totally disagree."

\section{Exposure assessment}

After the selection of the eight study sites and the collection of the survey data, the relevant source data for the final (high detail) noise exposure calculations were collected from army officials that were in command of the respective training grounds. Their task basically encompassed the reporting of the weapons and ammunitions used, the corre- sponding number of shots and shooting days, as well as the distribution of shots fired between day and evening (night shootings were very rare). Each weapon/ammunition combination was assigned one of the following categories: small caliber $(<10 \mathrm{~mm}$, e.g., assault rifles), middle caliber (10$100 \mathrm{~mm}$, e.g., antiaircraft guns), large caliber $(>=100 \mathrm{~mm}$, e.g., large tank cannons), grenades and explosive charges, mortars, and practice ammunition.

For all receiver points in the survey, the exposure from every emplacement/weapon/ammunition combination of the respective study site was calculated using the "WL04" source and propagation model developed by the Swiss Federal Laboratories for Materials Testing and Research (Empa). This model delivers exposure spectra in octave bands from $31.5 \mathrm{~Hz}$ to $4 \mathrm{kHz}$ of direct and reflected sounds as well as for each source and receiver combination and for up to 16 distinct weather conditions that were derived for each study site based on long-term weather statistics (the $16 \mathrm{~Hz}$ octave band was omitted as it does not relevantly contribute to the total exposure, even for large weapons). The model accounts for three types of sound sources: muzzle blasts, sonic booms, and detonations. Receiver points were set on the facade of the building aiming at the shooting ground. The height of the receiver points was set to $1.8 \mathrm{~m}$ for detached houses and ground floor apartments. For each additional floor, the height was increased by $2.6 \mathrm{~m}$. Exposure calculations were performed separately for the years 2004, 2005, and 2006 and separately for daytime and evening shootings. Shootings in the night past 23:00 $\mathrm{h}$ were extremely rare, as were shootings during weekends.

The total yearly exposure levels were calculated as the sum of the energetic products of each emplacement/weapon/ ammunition sound exposure level with their corresponding number of shots fired in the respective year.

As the timely distribution of the intensity of shooting often varies considerably across a year, a (daily) average exposure value, e.g., a $12 \mathrm{~h} L_{\text {eq }}$ or a $24 \mathrm{~h} L_{\text {eq }}$, does not in most cases reflect a meaningful description of the noise exposure residents are affected with. Dose values in this article are therefore simply given as $L_{E}$ values, representing the total (integrated) energy of shooting noise exposure in a year (or as the average over 3 years). A corresponding energy equivalent continuous level over a particular time period can be obtained by transforming the given $L_{E}$ value, e.g., using

$$
L_{\mathrm{eq}}=L_{E}-10 \log \left(N_{\mathrm{SD}} \times N_{\mathrm{HD}} \times 3600\right),
$$

where $L_{\text {eq }}$ is equivalent sound level for a particular number of hours of a particular number of days (within a year), $N_{\mathrm{SD}}$ is number of days in a year when shootings/trainings take place, $N_{\mathrm{HD}}$ is number of hours per day for which the average sound level should be calculated (e.g., 12). For example, the average daily $12 \mathrm{~h} L_{\mathrm{eq}}$ would thus be $L_{E}-10 \log (365 \times 12$ $\times 3600)$.

\section{RESULTS}

\section{A. Sample description}

A total of 460 male (46\%) and 542 female (54\%) participants constituted the sample of 1002 residents. Shooting 
TABLE I. Number of interviews conducted at each study site and per exposure category.

\begin{tabular}{|c|c|c|c|c|c|c|c|c|}
\hline $\begin{array}{l}\text { Study } \\
\text { site }\end{array}$ & $\begin{array}{c}90-95 \mathrm{~dB} \\
{\left[L_{\mathrm{AE}}\right]}\end{array}$ & $\begin{array}{c}95-100 \mathrm{~dB} \\
{\left[L_{\mathrm{AE}}\right]}\end{array}$ & $\begin{array}{c}100-105 \mathrm{~dB} \\
{\left[L_{\mathrm{AE}}\right]}\end{array}$ & $\begin{array}{c}105-110 \mathrm{~dB} \\
{\left[L_{\mathrm{AE}}\right]}\end{array}$ & $\begin{array}{c}110-115 \mathrm{~dB} \\
{\left[L_{\mathrm{AE}}\right]}\end{array}$ & $\begin{array}{c}115-120 \mathrm{~dB} \\
{\left[L_{\mathrm{AE}}\right]}\end{array}$ & $\begin{array}{c}120-125 \mathrm{~dB} \\
{\left[L_{\mathrm{AE}}\right]}\end{array}$ & $\begin{array}{c}125-130 \mathrm{~dB} \\
{\left[L_{\mathrm{AE}}\right]}\end{array}$ \\
\hline Bière & 14 & 21 & 50 & 42 & 51 & 42 & 10 & \\
\hline Chur & 1 & 15 & 62 & 56 & 23 & 2 & & \\
\hline Gehren-Erlinsbach & & 2 & 6 & 11 & 8 & 2 & & \\
\hline Herisau-Gossau & & 11 & 25 & 20 & 7 & & 1 & 2 \\
\hline Krähtal-Riniken & 1 & 5 & 25 & 16 & 10 & 1 & & \\
\hline Thun & & 7 & 27 & 59 & 92 & 52 & 34 & 8 \\
\hline Wangen an der Aare & & 15 & 10 & 8 & 12 & 3 & & \\
\hline Walenstadt & & 25 & 28 & 46 & 34 & & & \\
\hline Total & 16 & 101 & 233 & 258 & 237 & 102 & 45 & 10 \\
\hline Percent & 1.60 & 10.08 & 23.25 & 25.75 & 23.65 & 10.18 & 4.49 & 1.00 \\
\hline
\end{tabular}

noise exposure was calculated for 918 distinct receiver points. For a small number of the receiver points, more than one respondent were interviewed (e.g., more than one family member living in the same apartment). 232 interviews were made in the French speaking part of Switzerland. Respondents were in the age range from 16 to 94 years. The average age of the respondents was 50 years. The age class distribution was as follows (in parentheses are the percentages of the population older than 16 ): between 16 and 20 years: $5 \%$ (5\%); 20-40: 25\% (34\%); 40-60: 37\% (34\%); and older than 60 years: $33 \%(26 \%)$.

The respondents experienced yearly military shooting noise exposure levels at their homes between 92 and $130 \mathrm{~dB}$ $L_{\mathrm{AE}}$ or 98 and $141 \mathrm{~dB} L_{\mathrm{CE}}$, respectively. Unlike the (quite simple) preliminary calculations that were used for sample stratification and definition of the address sampling areas, the definitive exposure calculation for each respondent accounted for the elevation above ground and shielding effects from other buildings; thus yearly $L_{\mathrm{AE}}$ levels down to $92 \mathrm{~dB}$ were reached in the sample. Table I shows the distribution of the number of telephone interviews that were realized per $L_{\mathrm{AE}}$ exposure level category (as 3 year energetic average) and study site.

Table II shows the yearly average number of shots as well as the number of shots above the 50,60,70, and $80 \mathrm{~dB}$ $L_{\mathrm{AE}}$ thresholds per weapon type, as experienced at the 918 receiver points in the sample. The figures given in the last four columns represent the average number of shots above the respective threshold, which is defined as the average A-weighted sound exposure level of one individual shot of a distinct source (more clearly the emplacement/weapon/ ammunition combination) at the receiver points within the study sample, as the average of the 3 years 2004, 2005, and 2006.

The average shooting activity per year was about the same for all 3 years and no substantial changes have occurred at any of the eight grounds between 2004 and 2006.

\section{B. Annoyance ratings and exposure metrics}

In light of the different approaches to define high annoyance and for reasons of comparability, both ICBEN scales to assess (high) annoyance in the respondent (Fields et al., 2001) were part of the interview. Concerning the five-point verbal scale, ICBEN's recommendation is to use the upper two categories (the verbal marks "very" and "extremely") as indicators of high annoyance. This corresponds to a cutoff point at $60 \%$ of the scale. No recommendation is given for the 11-point scale, but according to common practice, the upper three points on the numerical scale $(8,9,10)$ define the presence of "high annoyance" in the respondent. In this case, the cutoff lies at $72.7 \%$ (see Schultz, 1978). In total, on the 11-point numerical scale, 170 of 1002 respondents qualified as highly annoyed, on the 5-point scale 241 of 1002.

The annoyance questions were asked in the following order: the first time during the interview using the 5-point verbal scale with the marks "not at all," "slightly," "moderately," "very," and "extremely" within a block of noise annoyance questions for different noise sources, and the second time later during the interview using the 11-point numerical scale. For all further quantitative analyses, the verbal answer alternatives of the five-point scale have been transformed to numerical values $1-5$ and treated as continuous.

TABLE II. Number of shots and number of shots above threshold at the 918 receiver points in the sample (all values represent the yearly average over the years 2004, 2005, and 2006).

\begin{tabular}{lcccccc}
\hline \hline $\begin{array}{l}\text { Type of weapon/ } \\
\text { ammunition }\end{array}$ & $\begin{array}{c}\text { No. of shots } \\
\text { during day }\end{array}$ & $\begin{array}{c}\text { No. of shots } \\
\text { during evening }\end{array}$ & $\begin{array}{c}\text { No. of shots } \\
>L_{\mathrm{AE}}=50 \mathrm{~dB}\end{array}$ & $\begin{array}{c}\text { No. of shots } \\
>L_{\mathrm{AE}}=60 \mathrm{~dB}\end{array}$ & $\begin{array}{c}\text { No. of shots } \\
>L_{\mathrm{AE}}=70 \mathrm{~dB}\end{array}$ & $\begin{array}{c}\text { No. of shots } \\
>L_{\mathrm{AE}}=80 \mathrm{~dB}\end{array}$ \\
\hline $\begin{array}{l}\text { Large caliber } \\
\text { Middle caliber }\end{array}$ & 5088 & 179 & 2119 & 1701 & 834 & 207 \\
Small caliber & 336351 & 11808 & 38141 & 18954 & 17194 & 14699 \\
Practice ammunition & 8554533 & 532128 & 303277 & 179902 & 73783 & 0 \\
Grenades/explosive charges & 32650 & 4862 & 0 & 0 & 0 & 0 \\
Mortars & 17163 & 1065 & 2356 & 1712 & 12671 \\
\hline \hline
\end{tabular}


TABLE III. Mean annoyance and percent highly annoyed (\%HA) for different degrees of exposure. The categories are defined based on the $L_{\mathrm{AE}}$ metric, the average exposure values $\varnothing-L_{\mathrm{AE}}$ and $\varnothing-L_{\mathrm{CE}}$ pertain to the arithmetic average of all cases within the category boundaries. $N$ refers to the number of cases in each exposure level category.

\begin{tabular}{|c|c|c|c|c|c|c|}
\hline $\begin{array}{l}\text { Level category } \\
\text { (range of } L_{\mathrm{AE}} \text { values) }\end{array}$ & Scale & Mean annoyance & CI $-95 \%$ & $\mathrm{CI}+95 \%$ & St. dev. & $\% \mathrm{HA}$ \\
\hline $90-95(N=16)$ & 11 -point $[0, \ldots, 10]$ & 3.38 & 2.12 & 4.63 & 2.36 & 6.25 \\
\hline $\begin{array}{l}\varnothing-L_{\mathrm{AE}}=93.64 \\
\varnothing-L_{\mathrm{CE}}=114.87\end{array}$ & 5 -point $[1, \ldots, 5]$ & 1.81 & 1.46 & 2.16 & 0.66 & 0.00 \\
\hline $95-100(N=101)$ & 11 -point $[0, \ldots, 10]$ & 2.83 & 2.27 & 3.40 & 2.86 & 7.92 \\
\hline $\begin{array}{l}\varnothing-L_{\mathrm{AE}}=98.07 \\
\varnothing-L_{\mathrm{CE}}=111.50\end{array}$ & 5 -point $[1, \ldots, 5]$ & 2.10 & 1.89 & 2.31 & 1.05 & 7.92 \\
\hline $100-105(N=233)$ & 11 -point $[0, \ldots, 10]$ & 3.83 & 3.47 & 4.19 & 2.77 & 10.73 \\
\hline $\begin{array}{l}\varnothing-L_{\mathrm{AE}}=102.67 \\
\varnothing-L_{\mathrm{CE}}=116.37\end{array}$ & 5 -point $[1, \ldots, 5]$ & 2.41 & 2.26 & 2.55 & 1.12 & 15.45 \\
\hline $105-110(N=258)$ & 11 -point $[0, \ldots, 10]$ & 4.14 & 3.77 & 4.51 & 3.00 & 16.28 \\
\hline $\begin{array}{l}\varnothing-L_{\mathrm{AE}}=107.53 \\
\varnothing-L_{\mathrm{CE}}=119.66\end{array}$ & 5 -point $[1, \ldots, 5]$ & 2.53 & 2.38 & 2.68 & 1.20 & 23.26 \\
\hline $110-115(N=237)$ & 11 -point $[0, \ldots, 10]$ & 4.65 & 4.26 & 5.03 & 3.03 & 22.78 \\
\hline $\begin{array}{l}\varnothing-L_{\mathrm{AE}}=112.30 \\
\varnothing-L_{\mathrm{CE}}=123.77\end{array}$ & 5 -point $[1, \ldots, 5]$ & 2.97 & 2.82 & 3.13 & 1.24 & 32.07 \\
\hline $115-120(N=102)$ & 11 -point $[0, \ldots 10]$ & 5.35 & 4.78 & 5.92 & 2.91 & 28.43 \\
\hline $\begin{array}{l}\varnothing-L_{\mathrm{AE}}=117.32 \\
\varnothing-L_{\mathrm{CE}}=129.21\end{array}$ & 5 -point $[1, \ldots, 5]$ & 3.41 & 3.18 & 3.65 & 1.20 & 43.14 \\
\hline $120-125(N=45)$ & 11 -point $[0, \ldots, 10]$ & 5.09 & 4.30 & 5.88 & 2.63 & 22.22 \\
\hline $\begin{array}{l}\varnothing-L_{\mathrm{AE}}=122.21 \\
\varnothing-L_{\mathrm{CE}}=131.40\end{array}$ & 5 -point $[1, \ldots, 5]$ & 3.11 & 2.78 & 3.44 & 1.09 & 35.56 \\
\hline $125-130(N=10)$ & 11 -point $[0 \ldots 10]$ & 3.90 & 1.68 & 6.12 & 3.11 & 10.00 \\
\hline $\begin{array}{l}\varnothing-L_{\mathrm{AE}}=127.74 \\
\varnothing-L_{\mathrm{CE}}=134.09\end{array}$ & 5 -point $[1, \ldots, 5]$ & 2.60 & 2.00 & 3.20 & 0.84 & 10.00 \\
\hline
\end{tabular}

Using linear regression models, it was first assessed which exposure metrics appear to be the best predictors of annoyance. The following potential predictors were investigated: Total energetic and arithmetic average (over 3 years) sound exposure levels $\left(L_{\mathrm{AE}}\right.$ and $\left.L_{\mathrm{CE}}\right)$, energetic and arithmetic average sound exposure level $\left(L_{\mathrm{AE}}\right.$ and $\left.L_{\mathrm{CE}}\right)$ during day and during evenings, energetic average sound exposure level $\left(L_{\mathrm{AE}}\right.$ and $\left.L_{\mathrm{CE}}\right)$ of small caliber shots and of large caliber shots, total number of small caliber shots over $50 \mathrm{~dB} L_{\mathrm{AE}}$, and total number of large caliber shots over $98 \mathrm{~dB} L_{\mathrm{CE}}$. From these preliminary analyses, it became evident that the basic energetic dose measures $L_{\mathrm{AE}}$ and $L_{\mathrm{CE}}$ are the best predictors for shooting noise annoyance. Table III tabulates the mean annoyance rating per exposure level category as well as the percentage of highly annoyed persons (\%HA) in each category, according to the "standard" cutoff points (5-point: 60\%; 11-point: $72.7 \%$ ) on the scales.

Annoyance is an increasing function of the sound exposure level up to the exposure level category of 115-120 dB $L_{\mathrm{AE}}$. Contrary to expectation, within the higher level categories (120-125 and 125-130 dB $\left.L_{\mathrm{AE}}\right)$, mean annoyance as well as the percentage of highly annoyed persons (\%HA) drop to a level close to the level reported by respondents that are 15 or even $20 \mathrm{~dB}$ less exposed. This could be explained by some types of self-selection process being at work insofar as people not being annoyed by military shooting noise are over-represented in areas close to military shooting grounds, maybe because they are less sensitive to noise and/or have a more positive attitude toward the army, e.g., because they are army employees that live in the vicinity of their employer. This explanation appears feasible since (a) noise sensitivity (as measured by the LEFK) is a significant negative predictor of the exposure, as expressed in the $L_{\mathrm{AE}}$ in linear regression analysis $[\beta=-0.11, t(1000)=-2.33, p=0.02]$; (b) annoyance, as measured using the five-point verbal scale, and attitude toward the army (an index value between 1 and 5 with higher values denominating a more positive attitude, derived from items of the questionnaire, see Sec. II B) is negatively correlated within the sample $[r=-0.28 ; p<0.0001]$. (b) Furthermore, in general linear modeling of annoyance (fivepoint verbal scale), both $L_{\mathrm{AE}}$ and attitude independently predict annoyance $\left[L_{\mathrm{AE}}: F(1)=94.23, p<0.0001 ;\right.$ attitude: $F(1)=89.64, p<0.0001]$, whereas attitude is negatively related to annoyance in this model.

The annoyance ratings showed considerable variability as can bee estimated from the confidence intervals reported in Table III. Linear regression results of the individual data (not the grouped data) for the 11-point numerical scale yielded $R^{2}$ values of less than 0.05 , and the 5-point verbal scale yielded an adjusted $R^{2}$ value of 0.08 for both $L_{\mathrm{AE}}$ and $L_{\mathrm{CE}}$ as predictor. While with transportation noise, on the individual level, $R^{2}$ values between 0.1 and 0.2 are common, the marginal relationship found with military shooting noise is no surprise, assuming that individual moderators more strongly influence the annoyance rating than would be the case with transportation noise. 
TABLE IV. Logistic regression analysis results of $P_{\mathrm{HA}}$ explained by $L_{\mathrm{AE}}$ and individual moderators. Noise sensitivity was assessed using the LEFK questionnaire and is expressed on a scale from 0 to 27 . Attitude toward the army is expressed on a scale from 1 to 5 .

\begin{tabular}{lccccc}
\hline \hline Dependent & Parameter & Coefficient $(B)$ & Standard error & Wald stat. & $\mathrm{p}$ \\
\hline$P_{\mathrm{HA}}$ (five-point, cutoff 60\%) & Intercept & -10.12 & 1.36 & 55.81 & $<0.0001$ \\
& $L_{\mathrm{AE}}$ & 0.09 & 0.01 & 52.81 & $<0.0001$ \\
& Noise sensitivity & 0.08 & 0.02 & 20.75 & $<0.0001$ \\
& Attitude toward & & & \\
& army & -0.45 & 0.07 & 46.31 & $<0.0001$ \\
& & McKelvey and Zavoina $R^{2}: 0.45$ & \\
\hline \hline
\end{tabular}

\section{Exposure-effect relationships for $L_{\mathrm{AE}}$ and $L_{\mathrm{CE}}$ as principal predictors}

The derivation of a fitting function in order to formalize an exposure-effect relationship requires practical- as well as theory-based choices about the functional form with which the observed exposure-effect relationship can be represented in a pertinent and useful way. Since the relevant effect in the current study — being highly annoyed or not—is binary by nature, the logistic form is preferable. To predict the proportion of highly annoyed persons at any given $L_{E}$ level, a sound statistical model must prevent of predicting values that are theoretically inadmissible; the statistical analysis must therefore account for the binomial nature of the distribution of the dependent variable. This is achieved with logistic regression analysis. Logistic regression analyses on the probability of high annoyance $\left(P_{\mathrm{HA}}\right)$ using the $L_{\mathrm{AE}}$ and $L_{\mathrm{CE}}$ predictor were calculated with the SAS STAT system (SAS VERSION 9, SAS Institute, Cary, NC). To roughly assess the degree of explained variance in the model building process, the pseudo- $R^{2}$ statistic according to McKelvey and Zavoina (1975) was calculated.

First, it was assessed which nonacoustic factors exert influence on the probability of high annoyance $P_{\mathrm{HA}}$ (on the five-point verbal scale). The language in which the interview was conducted (French or German) did not have a significant effect on the reported annoyance. Also, no significant effect of gender on annoyance could be found in a range of models. There could be found an influence of age in a few models though, insofar as elderly persons were less annoyed than younger. No effect was found with the duration of living near the shooting ground, nor did house owner's annoyance significantly differ from the annoyance of tenants. The best logistic model comprised the predictors $L_{\mathrm{AE}}$, attitude toward the army and noise sensitivity (as measured by the LEFK). To permit the readers to gauge the relative impact of these variables in a composite model, the corresponding parameter estimates are given in Table IV.

Since individual moderators of noise annoyance cannot be accounted for within the scope of noise legislation and abatement policy, and also because no other operational characteristics of shooting appeared to be relevant in their influence on annoyance, here, a set of logistic models is proposed which solely rely on either the $L_{\mathrm{AE}}$ or $L_{\mathrm{CE}}$ dose measure as main predictor. In the following analyses, to simplify matters, only the $L_{\mathrm{AE}}$ metric is further used. However, the $L_{\mathrm{CE}}$ metric would almost equally well serve the same purpose.
The two types of annoyance scales and their most common cutoff points for the "HA" definition did not lead to congruent exposure-effect curves (see Fig. 1). This points to the fact that the numerical and the verbal scales and their most commonly used cutoff points for the HA definition obviously do not measure the same thing. There have been successful attempts to attain congruent curves in other studies (e.g., Schreckenberg and Meis, 2006) by statistically raising the cutoff point of the five-point scale to $72 \%$ by weighting the response category "very" on the five-point scale as proposed by Miedema and Vos (1998). A similar attempt was not very successful with the current data. The weighted curve (which corresponds to a cutoff point at $72 \%$ ) from the 5 -point scale is displaced by about $10 \mathrm{~dB}$, but has a more steep characteristic than the dose-response curve based on the 11-point scale. The parameters of the corresponding weighted logistic regression are tabulated in the last rows in Table V.

Although the issue of noncongruent exposure-effect curves from scales that are both designed to assess high annoyance is important for noise effects research and for noise policy in general, the discrepancy of the measurement result with military shooting noise cannot be investigated any further within the scope of the present article. The question about which of the three displayed curves better serves policy purposes will be discussed in Sec. IV.

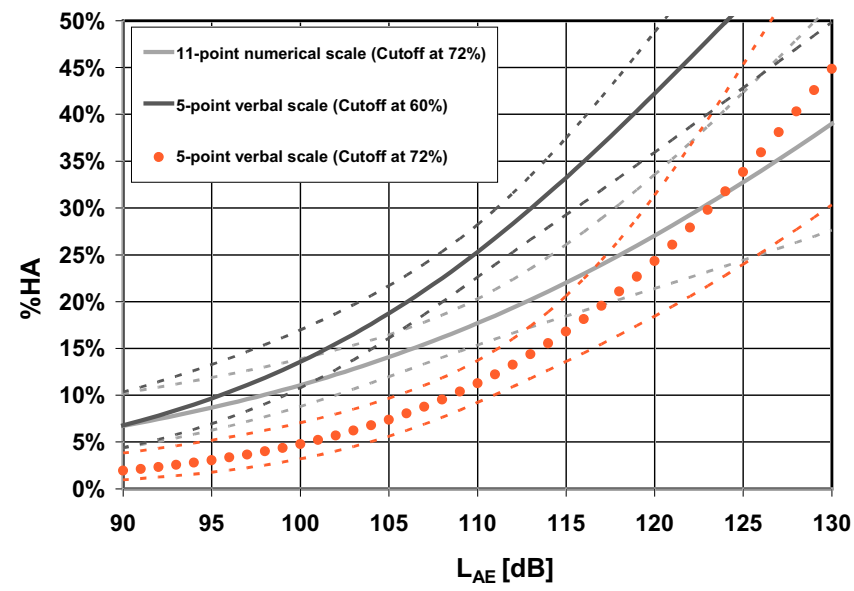

FIG. 1. Logistic dose-response curves and 95\% confidence intervals for three different methods of defining the percentage of highly annoyed persons in the current sample. The curve based on the 5-point verbal scale that uses a cutoff point of $72 \%$ was generated by weighting the cases, where the respondent chose the "very" modifier on the scale, with 0.4 in the logistic regression analysis. 
TABLE V. Results of the logistic regression analyses of $P_{\mathrm{HA}}$ with $L_{\mathrm{AE}}$ or $L_{\mathrm{CE}}$ as only predictor.

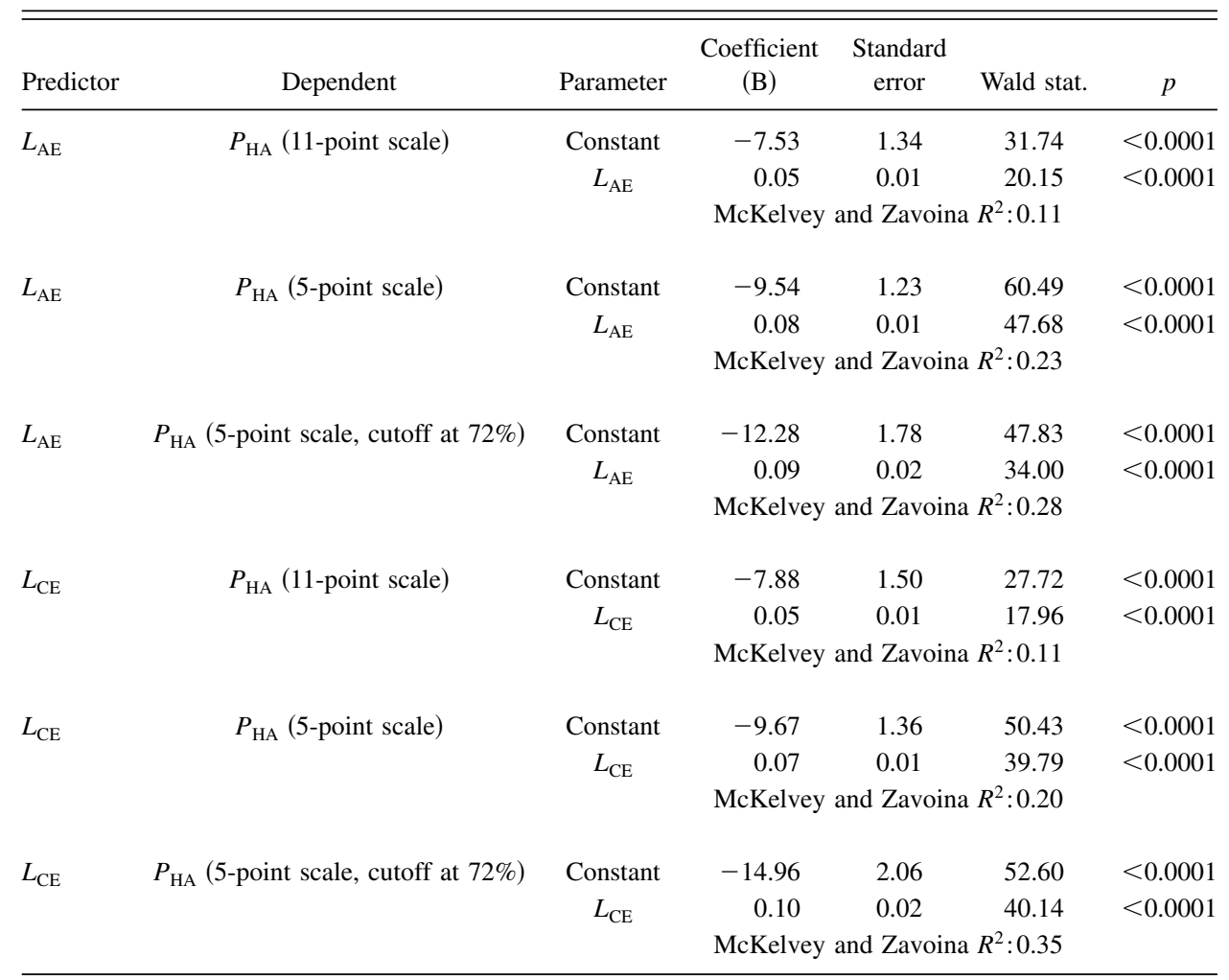

The confidence intervals of the functions in Fig. 1 and the standard errors reported in Table $\mathrm{V}$ pertain to the uncertainty of the annoyance measurement in the sample, not the uncertainty of noise exposure calculations. Therefore, the true confidence boundaries are most probably wider. The extended uncertainty of the exposure-effect relationship was not calculated since the nonconsideration of acoustic measurement uncertainty is a shortcoming of almost all annoyance studies of this kind, and accounting for acoustic uncertainty would possibly compromise the comparability of the confidence intervals in this study with the ones from other studies.

\section{Accounting for low frequency components in $L_{\mathrm{AE}}$ based linear and binary logistic regression models}

The sound exposure spectra of large caliber weapons, such as tank cannons, are dominated by the energy in the low frequency bands. For this kind of shooting events, $\mathrm{C}$-weighted measures might better predict annoyance. In the literature, e.g., in Vos, 2001, there have been discussed models which account for both A-weighted and C-weighted properties of shooting sounds. The aim of such kind of modeling is to arrive at one single rating procedure for both small- and medium-large weapon sounds. The following analyses were performed to test the benefits of the inclusion of C-weighted measures in the prediction of (high) annoyance. It must be noted that the proportion of heavy weapon shooting events, which react much stronger to $\mathrm{C}$-weighted measurements, is relatively small in the current sample. Thus the following analyses do not necessarily reflect a situation with considerably more intense heavy weapons shooting activity.

\section{Linear models}

The degree of annoyance, as measured with the 11- and 5-point scales, was modeled with linear regression analysis (GLM Module of STATistica 7, Stat Soft Inc., Tulsa, OK) with the two predictors $L_{\mathrm{AE}}$ and the difference between the C-weighted and the A-weighted levels $\left(L_{\mathrm{CE}}-L_{\mathrm{AE}}\right)$, as has been suggested by Vos (2001). The inclusion of this second predictor is based on the idea that for large weapons with considerable low frequency content, the A-weighted level alone does not sufficiently account for the variation in annoyance. The results are presented in Table VI.

Both predictors, $L_{\mathrm{AE}}$ and $\left(L_{\mathrm{CE}}-L_{\mathrm{AE}}\right)$, account for the variance in annoyance. The inclusion of $\left(L_{\mathrm{CE}}-L_{\mathrm{AE}}\right)$ as a second predictor slightly improved the explained variance $\left(R^{2}\right.$ adjusted) of both the models by about 0.01 points. Also, as can be learned from Table VI, answers on the 5-point verbal scale better predicted the annoyance rating than did the 11point numerical scale.

It must be noted that $\left(L_{\mathrm{CE}}-L_{\mathrm{AE}}\right)$ is strongly dependent on weapon type. With small arms, the difference is near 0 $\mathrm{dB}$, and increases with increasing caliber, as the low frequency energy becomes more and more determining. In the current sample, the arithmetic average C-A level differences at the receiver points for the different weapon categories were as follows (rounded to full numbers): large caliber: 19 $\mathrm{dB}$; middle caliber: $10 \mathrm{~dB}$; small caliber: $3 \mathrm{~dB}$; practice ammunition: $5 \mathrm{~dB}$; grenades/explosive charges: $16 \mathrm{~dB}$; mortars: $16 \mathrm{~dB}$.

Albeit the most important components determining annoyance due to military shooting noise most probably are outside the acoustic domain (but rather considering individual moderators such as noise sensitivity and attitude to- 
TABLE VI. Results of the linear regression analyses on the annoyance rating with $L_{\mathrm{AE}}$ and $\left(L_{\mathrm{CE}}-L_{\mathrm{AE}}\right)$ as predictors.

\begin{tabular}{lcrcrcccc}
\hline \hline Dependent & Parameter & \multicolumn{1}{c}{$B$} & Beta & $F$ & df & $p$ & Whole model statistics \\
\hline Annoyance rating & Intercept & -7.36 & & 21.06 & 1 & 0.0001 & \\
(11-point scale) & $L_{\mathrm{AE}}$ & 0.10 & 0.23 & 50.89 & 1 & $<0.0001$ & $R^{2}$ adj. $=0.05 ; F(2)=26.08, p<0.0001$ \\
& $\left(L_{\mathrm{CE}}-L_{\mathrm{AE}}\right)$ & 0.07 & 0.10 & 10.42 & 1 & 0.0013 & \\
& & & & & & & \\
Annoyance rating & Intercept & -3.70 & & 33.01 & 1 & $<0.0001$ & \\
(5-point scale) & $L_{\mathrm{AE}}$ & 0.06 & 0.03 & 101.15 & 1 & $<0.0001$ & $R^{2}$ adj. $=0.09 ; F(2)=50.59, p<0.0001$ \\
& $\left(L_{\mathrm{CE}}-L_{\mathrm{AE}}\right)$ & 0.02 & 0.03 & 8.11 & 1 & 0.0045 & \\
\hline \hline
\end{tabular}

ward the army, see Sec. III C), the results at hand confirm the predictive value of incorporating the difference between $\mathrm{C}$ and A-weighted measurements. However, in light of the comparatively small effect of acoustic predictors anyway, the additional variance explanation appears negligible.

\section{Binary logistic models}

Two binary logistic models that predict the probability of high annoyance $\left(P_{\mathrm{HA}}\right)$ with $L_{\mathrm{AE}}$ and $\left(L_{\mathrm{CE}}-L_{\mathrm{AE}}\right)$ as independent variables were estimated using the procedure LOGISTIC of SAS. The results are presented in Table VII.

In contrast to linear modeling of the annoyance rating (see Table VI), the inclusion of $\left(L_{\mathrm{CE}}-L_{\mathrm{AE}}\right)$ in the binary logistic models did not significantly contribute to the prediction of the probability of high annoyance $\left(P_{\mathrm{HA}}\right)$. It therefore appears not necessary to implement $\mathrm{C}$-weighted measurements or a difference between the C- and A-weighted levels in the modeling of exposure-effect functions.

\section{DISCUSSION}

As military shooting noise resulting from training activities in times of peace is less of a problem for the majority of the population, there are relatively few reports about such noise effects to be found and hence the impact of military shooting noise from training grounds of armies is far less well understood than effects of traffic or industrial noise. The current research therefore investigated shooting noise annoyance of residents in communities near eight large military training grounds by means of a field study. In the following, the study design and main findings are briefly discussed.

\section{A. Study design and response rate}

The chosen study procedure basically adopted a protocol that is standard practice in so called "socioacoustic surveys" where in the first stage, study sites with relevant noise exposure are identified, and then a stratified sample of residents is drawn, which then are finally interviewed. In contrast to laboratory studies-which somehow reflect the "traditional" form of investigating shooting noise annoyance-in field studies control over the noise emitting factors is limited. Limited control can-as in the current case-lead to certain imbalances. For example, the number of large caliber weapon rounds in the current sample is considerably smaller than for other weapon types, thus the results may not be applied to grounds with predominantly large weapon shooting activity. A perfectly balanced study would probably better allow making inferences as to the annoying potential of such weapons and concerning the differences in annoyance between small and large weapons. However, perfectly balanced field studies of noise exposure and annoyance are in many cases unaccomplishable, as different types of noise events from a particular noise emitting installation are not necessarily equally distributed (e.g., there are usually less heavy airplanes than light ones at airports and one almost always finds more passenger cars than trucks on roads). The current study aimed at elucidating the exposure-effect relationship as shooting is experienced in a real setting, and this includes also that the proportions of different weapons account for the overall "sound impression" in a representative manner.

The response rate of $27 \%$ in the CATI interviews was relatively small, but not really uncommon. A lot of studies that require (notably unpaid) people to respond by complet-

TABLE VII. Results of the logistic regression analyses on $P_{\mathrm{HA}}$ with $L_{\mathrm{AE}}$ and $\left(L_{\mathrm{CE}}-L_{\mathrm{AE}}\right)$ as predictors.

\begin{tabular}{lccccc}
\hline \hline Dependent & Parameter & Coefficient $(B)$ & Standard error & Wald stat. & $p$ \\
\hline$P_{\mathrm{HA}}$ (11-point scale) & Intercept & -8.30 & 1.51 & 30.34 & $<0.0001$ \\
& $L_{\mathrm{AE}}$ & 0.06 & 0.01 & 21.23 & $<0.0001$ \\
& $\left(L_{\mathrm{CE}}-L_{\mathrm{AE}}\right)$ & 0.02 & 0.02 & 1.27 & 0.2592 \\
& \multicolumn{5}{c}{ McKelvey and Zavoina $R^{2}: 0.14$} \\
& Intercept & -10.36 & 1.38 & 56.79 & $<0.0001$ \\
$P_{\mathrm{HA}}(5$-point scale) & $L_{\mathrm{AE}}$ & 0.08 & 0.01 & 48.65 & $<0.0001$ \\
& $\left(L_{\mathrm{CE}}-L_{\mathrm{AE}}\right)$ & 0.02 & 0.02 & 1.84 & 0.1753 \\
& \multicolumn{5}{c}{ McKelvey and Zavoina $R^{2}: 0.22$} \\
\end{tabular}


ing a questionnaire face the growing threat of nonresponse. Response rates to household telephone surveys are diminishing because of changes in telecommunications, marketing, and culture (O'Toole et al., 2008). Evidence is most compelling from long-term trend surveys that have been repeated over many years. One possible explanation might be that people are getting more and more reluctant to take part in telephone surveys, especially because "phone spam" is increasing. Many callees perhaps reflexively refused to talk to the interviewers on the telephone, wrongly assuming that the caller has some commercial interests.

\section{B. Exposure-annoyance relationship}

Establishing the criteria for rating weapon noise has proven to be a quite difficult task as annoyance ratings from residents were strongly influenced by nonacoustic, but quite powerful moderating factors such as the attitude toward the army and the individual noise sensitivity (see Table IV). The results show that an energy type of model such as one based on $L_{\mathrm{AE}}$ or $L_{\mathrm{CE}}$ is the best available descriptor for community response to shooting with military weapons-a finding which is in line with previous research (Schomer, 1985). However, the relationship between the reactions of the respondents and exposure was not very strong for any exposure measure. The weak exposure-annoyance link was expected and is quite in line with previous attempts of deriving exposure-effect relationships of shooting noise annoyance in field studies (e.g., Bullen et al., 1991).

In light of the fact that only a few field studies on community reactions to military noise have been carried out so far, and many of these did not report a statistically modeled exposure-effect function at all, any attempt to compare the current findings with previous research is difficult. The only study that allows a more or less direct comparison with the current one was the one from Buchta and Vos (1998). They conducted a field study on annoyance from artillery firing and found $25 \% \mathrm{HA}$ at a $L_{\mathrm{CDN}}$ of about $57 \mathrm{~dB}$. Since in the current case, night and evening shootings are very rare, the $L_{\mathrm{DN}}$ is practically equal to the $L_{\mathrm{eq}, 24 \mathrm{~h}}$. The $L_{\mathrm{CDN}}$ level of 57 $\mathrm{dB}$ roughly corresponds to a yearly $L_{\mathrm{CE}}$ level of $132 \mathrm{~dB}$. In Fig. 1 one can find 25\% HA (using the 11-point scale and cutoff point at $72 \%$ ) at an $L_{\mathrm{CE}}$ of about $131 \mathrm{~dB}$. The two field studies thus appear to correspond quite well.

\section{Annoyance scales and cutoff points}

Schultz (1978) already observed that the largest uncertainties in deriving his influential dose-effect curve were associated with the judgment as to which respondents are counted as highly annoyed. Obviously, this is a statement that still holds. When applying the most commonly used cutoff points $(60 \%$ and $72.7 \%)$ on both the verbal and numerical annoyance scales suggested by ICBEN (Fields et al., 2001), the two resulting logistic curves are non-congruent and predict different amounts of highly annoyed persons (\%HA), especially within higher exposure level categories. The data also demonstrate that statistically aligning the cutoff points of both scales using the weighting method described by Miedema and Vos (1998) might not necessarily be a sound basis for comparing the two scales.

However, the observation that the \% $\mathrm{HA}$ predictions from the two scales do not match and the ratings on the five-point scale are higher might also be the result of an order effect and not necessarily an effect of the underlying scale: The annoyance question using the five-point verbal scale was asked first and early in the interview, after a few non-noise related questions were asked. On the contrary, the 11-point numerical scale was presented after the interview dealt with several noise related questions. The cognitive occupation with the noise topic could have lead to a relativization of the noise annoyance issue and may prevent the respondents to give extreme answers.

The results strongly suggest that the 5-point scale better explains variance, at least for shooting noise annoyance, than the 11-point scale. The explained variance of the 5-point scale is even a bit higher when applying a cutoff point at $72 \%$ instead of $60 \%$ (see Table V).

\section{Frequency weighting}

The observations made in previous laboratory studies (e.g., Vos, 2001), that explained variability of annoyance (slightly) rises when including the difference between the $\mathrm{C}$ and A-weighted levels as an additional predictor, could be confirmed in linear regression analyses. However, the additional variance explanation through incorporation of the $L_{\mathrm{CE}}-L_{\mathrm{AE}}$ difference was rather small and disappeared within the scope of binary logistic modeling of the probability of high annoyance. The $L_{\mathrm{CE}}-L_{\mathrm{AE}}$ predictor does not seem to offer a specific benefit that would warrant the effort of additional calculation or measurement of $\mathrm{C}$-weighted exposure levels.

In the present study, $L_{\mathrm{AE}}$ and $L_{\mathrm{CE}}$ equally well (or bad) predict annoyance and both descriptors can basically be used interchangeably as main predictor. The use of $\mathrm{C}$-weighting has some advantages when it comes to measurement instead of calculation, but only at relatively high exposure levels. This advantage is again outweighed by the high sensitivity of C-weighted measurements to wind noises. The use of $L_{\mathrm{AE}}$ (or alternatively $L_{\mathrm{CE}}$ ) as the sole predictor of high annoyance in most cases captures as much variation as is appropriately derivable from operational and acoustical data, at least in the vicinity of military shooting grounds where shooting takes place predominantly with small- and midsized caliber weapons. As the $L_{\mathrm{CE}}-L_{\mathrm{AE}}$ difference becomes larger with larger calibers, the incorporation of $\mathrm{C}$-weighted measurements might lead to a better prediction of annoyance at grounds with more heavy weapon shooting activities and/or considerably higher levels of exposure, or in countries with usually more permeable building envelopes.

In the literature of noise effects from military weapons, the presence of vibrations and rattle is reported to be the strongest adverse impulsive noise factor, and that a $\mathrm{C}$-weighted measure is the best available standard weighting for including those spectral bands responsible for building rattle (Schomer, 1985). Although quite a few respondents in 
the current sample reported to be particularly annoyed by rattle (Brink et al., 2008), rattle appears as not being that important factor in Switzerland as it possibly is in other countries with less rigorous construction standards for detached houses, e.g., in the United States.

\section{E. Policy recommendations}

It appears that exposure itself is only a moderate determinant of people's propensity for shooting noise annoyance. The current results suggest studies of community noise annoyance to basically keep with the five-point verbal scale since it features a larger degree of explained variance of annoyance.

The curve(s) based on the five-point scale and employing a cutoff point at $60 \%$ of the scale length can be expressed as second order polynomial with sufficient accuracy in the relevant exposure range with $P_{\mathrm{HA}}$ expressing the fraction of highly annoyed persons for a given $L_{\mathrm{AE}}$ or $L_{\mathrm{CE}}$ value, as follows:

$$
\begin{aligned}
\text { Using } L_{\mathrm{AE}}: P_{\mathrm{HA}}= & 1.404329-0.034881 \times L_{\mathrm{AE}} \\
& +0.000222 \times L_{\mathrm{AE}}{ }^{2} . \\
\text { Using } L_{\mathrm{CE}}: P_{\mathrm{HA}}= & 1.696684-0.036492 \times L_{\mathrm{CE}} \\
& +0.000202 \times L_{\mathrm{CE}}^{2}
\end{aligned}
$$

These curves represent military shooting noise annoyance which predominantly occurs with (1) most of the shootings taking place during day, (2) a fraction of about $5 \%-10 \%$ of the shootings taking place during the evening hours, and (3) no shootings during the core night hours. Furthermore, the curve rather represents an exposure situation with a considerable portion of small caliber shots (see Table II). With the advent of more sophisticated training simulators for mainly heavy weapon systems (e.g., for tanks), which will more and more replace the training with real weapons, large caliber weapon noise will most probably be less of a problem in the future. The proposed exposure-effect relationship for small caliber dominated shooting activity appears to be well suited to forecast shooting noise annoyance in the Swiss population-e.g., for regulatory purposes-and is possibly also applicable to similar shooting grounds in other European countries. It might be applied to military installations on the continental United States only with reservation, as (primarily) spatial and climatic conditions as well as cultural peculiarities such as construction standards for buildings considerably differ between the two countries.

\section{ACKNOWLEDGMENTS}

This study was funded by the Swiss Federal Office for the Environment to which we are very grateful. We thank the Swiss Federal Statistical Office for their collaboration with address sampling and IHA GfK for carrying out the telephone interviews for us. We also thank the Swiss Army for providing operational data in order to make the exposure calculations. We wish to express our gratitude to Rainer Guski and Christian Maschke for commenting an early version of the manuscript as well as to Hans Boegli and Kurt
Heutschi for other helpful contributions. Finally, M.B. would like to acknowledge the valuable discussions, in particular, with Joos Vos, but also with Jim Fields and Dick Botteldooren about several aspects of this study during the 9th ICBEN Conference at Foxwoods, CT in 2008.

Brink, M., Wunderli, J.-M., and Boegli, H. (2008). "Community response to military shooting noise immissions-Preliminary results," paper presented at the 9th International Congress on Noise as a Public Health Problem (ICBEN), Foxwoods, CT.

Buchta, E. (1990). "A field survey on annoyance caused by sounds from small firearms," J. Acoust. Soc. Am. 88, 1459-1467.

Buchta, E., and Vos, J. (1998). "A field survey on the annoyance caused by sounds from large firearms and road traffic," J. Acoust. Soc. Am. 104, 2890-2902.

Bullen, R. B., and Hede, A. J. (1982). "Assessment of community noise exposure from rifle shooting," J. Sound Vib. 82, 29-37.

Bullen, R. B., Hede, A. J., and Job, R. F. S. (1991). "Community reaction to noise from an artillery range," Noise Control Eng. J. 37, 115-128.

Fidell, S., Horonjeff, R., Schultz, T., and Teffeteller, S. (1983). "Community response to blasting," J. Acoust. Soc. Am. 74, 888-893.

Fields, J. M., De Jong, R. G., Gjestland, T., Flindell, I. H., Job, R. F. S., Kurra, S., Lercher, P., Vallet, M., Yano, T., Guski, R., Felscher-Suhr, U., and Schumer, R. (2001). "Standardized general-purpose noise reaction questions for community noise surveys: Research and a recommendation," J. Sound Vib. 242, 641-679.

International Standards Organisation (2003). ISO 1996-1:2003 (AcousticsDescription, measurement and assessment of environmental noise Part 1). Levein, B., and Ahrlin, U. (1988). "Annoyance caused by shooting range noise," J. Sound Vib. 127, 589-592.

McKelvey, R. D., and Zavoina, W. (1975). "Statistical model for the analysis of ordinal level dependent variables," J. Math. Sociol. 4, 103-120.

Meloni, T., and Rosenheck, A. (1995). "Choice of frequency-weighting for the evaluation of weapon noise," J. Acoust. Soc. Am. 97, 3636-3641.

Miedema, H., and Vos, H. (1998). "Exposure-response relationships for transportation noise," J. Acoust. Soc. Am. 104, 3432-3445.

O’Toole, J., Sinclair, M., and Leder, K. (2008). "Maximising response rates in household telephone surveys," BMC Med. Res. Methodol. 8, 71.

Rylander, R., and Lundquist, B. (1996). "Annoyance caused by noise from heavy weapon shooting ranges," J. Sound Vib. 192, 199-206.

Schomer, P. D. (1985). "Assessment of community response to impulsive noise," J. Acoust. Soc. Am. 77, 520-535.

Schomer, P. D. (1986). "High-energy impulsive noise assessment," J. Acoust. Soc. Am. 79, 182-186.

Schomer, P. D. (1994). "New descriptor for high-energy impulsive sounds," Noise Control Eng. J. 42, 179-191.

Schomer, P. D., and Wagner, L. R. (1995). "Human and community response to military sounds. 2. Results from field-laboratory tests of sounds of small arms, 25-mm cannons, helicopters, and blasts," Noise Control Eng. J. 43, 1-14.

Schomer, P. D., Wagner, L. R., Benson, L. J., Buchta, E., Hirsch, K. W., and Krahe, D. (1994). "Human and community response to military soundsresults from field-laboratory tests of small-arms, tracked-vehicle, and blast sounds," Noise Control Eng. J. 42, 71-84.

Schreckenberg, D., and Meis, M. (2006). "Belästigung durch Fluglärm im Umfeld des Frankfurter Flughafens [Endbericht; Langfassung] (Effects of aircraft noise on noise annoyance around frankfurt airport [unabridged final report])," available at http://www.dialogforum-flughafen.de/ fileadmin/PDF/Presse/Belaestigungsstudie_Langfassung.pdf (Last viewed 4/20/09).

Schultz, T. J. (1978). "Synthesis of social surveys on noise annoyance," J. Acoust. Soc. Am. 64, 377-405.

Sorensen, S., and Magnusson, J. (1979). “Annoyance caused by noise from shooting ranges," J. Sound Vib. 62, 437-442.

Troldahl, V. C., and Carter, R. E. (1964). "Random selection of respondents within households in phone surveys," J. Mark. Res. 1, 71-76.

Vos, J. (1990). "On the level-dependent penalty for impulse sound," J. Acoust. Soc. Am. 88, 883-893.

Vos, J. (2001). "On the annoyance caused by impulse sounds produced by small, medium-large, and large firearms," J. Acoust. Soc. Am. 109, 244253.

Vos, J. (2003). "A- and C-weighted sound levels as predictors of the annoy- 
ance caused by shooting sounds, for various facade attenuation types," J. Acoust. Soc. Am. 113, 336-347.

Vos, J., and Geurtsen, F. W. (2003). "On the assessment of shooting sounds: loudness-level weightings versus A- and C-weighted sound exposure lev- els (L)," J. Acoust. Soc. Am. 114, 1729-1732.

Zimmer, K., and Ellermeier, W. (1998). "Ein Kurzfragebogen zur Erfassung der Lärmempfindlichkeit (A short questionnaire to measure noise sensitivity)," Umweltpsychologie 2, 54-63. 